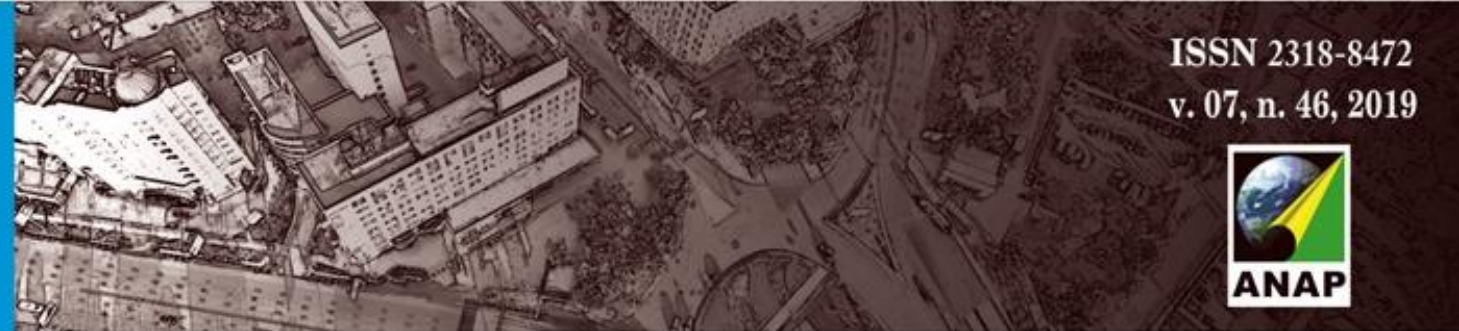

Revista Nacional de Gerenciamento de Cidades

\title{
Programa de inclusão da polpa do fruto da palmeira juçara na merenda escolar de Caraguatatuba/SP
}

\author{
Program of inclusion of pulp of the juçara palm fruit in the school lunch of \\ Caraguatatuba/SP
}

\begin{abstract}
Programa de inclusión de la pulpa del fruto de la palmera juçara en la merienda escolar de Caraguatatuba/SP
\end{abstract}

\section{Valéria Ferreira Macedo Costa}

Mestre em Ciências Ambientais pela Universidade Brasil, Fernandópolis, SP, Brasil valeriamcosta@gmail.com

\section{Gisele Herbst Vazquez}

Professora Doutora, Universidade Brasil, Fernandópolis, SP, Brasil gisele.vazquez@universidadebrasil.edu.br 


\section{RESUMO}

A juçara, Euterpe edulis, é uma palmeira típica da Mata Atlântica, ocupando vasta extensão territorial brasileira. Produz palmito de excelente qualidade, que para a sua exploração leva a planta a morte. Atualmente, a espécie encontra-se ameaçada de extinção devido a extração indiscriminada e ilegal do palmito aliada a perda dos agentes dispersores de suas sementes, como algumas aves frugívoras. A juçara vem sendo utilizada na merenda escolar de alguns municípios brasileiros atendendo ao artigo 14 da Lei no 11.947/2009, onde do total de recursos financeiros repassados no âmbito do Programa Nacional de Alimentação Escolar (PNAE), 30\% devem ser utilizados na aquisição de gêneros alimentícios, diretamente da agricultura familiar. Assim, o objetivo deste projeto foi incentivar o uso do fruto da polpa da palmeira juçara na merenda escolar em Caraguatatuba/SP. Para tanto, várias atividades foram realizadas em 2015: apresentação das qualidades nutricionais da polpa às nutricionistas, testes de aceitabilidade na Secretaria de Educação e em uma escola municipal, uma cartilha didática para colorir, aulas em powerpoint para distribuição na rede de ensino e o plantio de uma muda. Quanto aos testes, o suco de juçara foi $100 \%$ aceito pelos adultos e por $92 \%$ dos alunos, atingindo o porcentual de aceitação mínimo exigido pelo PNAE de $85 \%$. Por fim, vencidas as dificuldades burocráticas, o suco da polpa do fruto de juçara será inserido na merenda escolar de Caraguatatuba/SP, tendo sido efetuada em março de 2019 uma compra de $6000 \mathrm{~kg}$.

PALAVRAS-CHAVE: Sustentabilidade, extrativismo, Mata Atlântica.

\section{ABSTRACT}

The juçara, Euterpe edulis is a typical palm of the Atlantic Forest that occupies a vast Brazilian territorial extension. It produces excellent quality heart of palm, but its exploitation leads the plant to death. Currently the species is threatened with extinction due to the indiscriminate and illegal extraction of the palm heart and the loss of dispersing agents of its seeds like some frugivorous birds. Juçara has been used in the school meals of some Brazilian municipalities, in compliance with article 14 of Law No. 11,947/2009, where 30\% of the total financial resources passed through the National School Feeding Program (PNAE) should be used to acquire directly from family farming. Thus, the objective of this project was to encourage the use of the pulp fruit of the juçara palm in the school lunch in Caraguatatuba/SP. To do so, several activities were carried out in 2015: presentation of nutritional qualities of pulp to nutritionists, tests of acceptability in the Department of Education and in a municipal school, a didactic coloring book, PowerPoint classes for distribution in the teaching network and seedling planting. Regarding the tests, juçara juice was accepted by $100 \%$ of adults and $92 \%$ of students, and reaches the minimum acceptance percentage required by the PNAE, 85\%. Finally, after bureaucratic difficulties, juçara fruit pulp juice will be inserted in the school lunch of Caraguatatuba/SP, and in March 2019 a purchase of 6,000 kg.

KEYWORDS: Sustainability, extractivism, Atlantic Forest.

\section{RESUMEN}

La juçara, Euterpe edulis, es una palmera típica de la Mata Atlántica, ocupando una vasta extensión territorial brasileña. Produce palmito de excelente calidad, que para su explotación lleva a la planta a la muerte. Actualmente, la especie se encuentra amenazada de extinción debido a la extracción indiscriminada e ilegal del palmito aliada a la pérdida de los agentes dispersores de sus semillas, como aves frugívoras. La juçara ha sido utilizada en la merienda escolar de algunos municipios brasileños atendiendo al artículo 14 de la Ley no 11.947/2009, donde del total de recursos financieros repasados en el ámbito del Programa Nacional de Alimentación Escolar (PNAE), el 30\% debe ser utilizado en la adquisición de productos alimenticios, directamente de la agricultura familiar. El objetivo de este proyecto fue incentivar el uso del fruto de la pulpa de juçara en la merienda escolar en Caraguatatuba/SP. Para esto, actividades se realizaron en 2015: presentación de las calidades de la pulpa a nutricionistas, pruebas de aceptabilidad en la Secretaría de Educación y en una escuela municipal, una cartilla didáctica para colorear, clases en powerpoint para distribución en la red de enseñanza y la plantación de una muda. El jugo de juçara fue $100 \%$ aceptado por adultos y por el $92 \%$ de los alumnos, alcanzando el porcentaje de aceptación mínimo exigido por el PNAE del $85 \%$. Vencidas las dificultades burocráticas, el jugo de la pulpa del fruto de juçara será insertado en la merienda escolar de Caraguatatuba/SP, habiéndose efectuado en marzo/2019 una compra de $6.000 \mathrm{~kg}$.

PALABRAS CLAVE: Sostenibilidad, extractivismo, Mata Atlántica. 



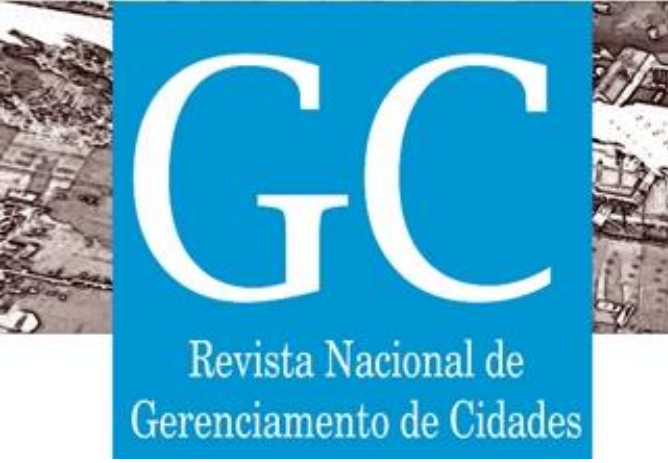

Nos últimos anos, entretanto, o manejo sustentável da espécie por meio do uso de seu fruto na alimentação humana, aliado a semeadura das sementes obtidas pelo despolpamento, vem sendo promovido por agências de pesquisa e desenvolvimento, empresas privadas, associações de agricultores e ONGs de vários estados brasileiros, o que abre uma esperança para a sobrevivência da espécie.

O uso dos frutos da palmeira para o preparo do "açaí de juçara", semelhante ao já popularizado açaí do norte, preparado com os frutos da palmeira Euterpe oleracea desde a década de 1980, vem ganhando destaque. Assim, dezenas de famílias de pequenos agricultores cultivam a palmeira juçara e comercializam a polpa dos frutos através de diversas iniciativas tais como feiras, cooperativas de consumidores e mercado institucional, gerando trabalho e renda, preservando a espécie (GONÇALVES et al., 2011).

Em 2009, o Programa Nacional de Alimentação Escolar (PNAE) passou a exigir que pelo menos $30 \%$ dos alimentos adquiridos nas escolas públicas sejam adquiridos de agricultores familiares (BRASIL, 2013) - exatamente aqueles que compreendem as comunidades que hoje produzem a polpa de juçara. Essa situação tem permitido que em várias áreas de estados brasileiros dentro do domínio da Mata Atlântica, a polpa de juçara faça parte da alimentação das crianças em idade escolar e que gere sustentabilidade às famílias produtoras.

Assim, prefeituras municipais como as de Três Cachoeiras/RS, Torres/RS, Mampituba/RS, Dom Pedro de Alcântara/RS, Sete Barras/SP e Ubatuba/SP introduziram a polpa do fruto de juçara na merenda escolar, com o intuito de atender à exigência do PNAE, melhorar a qualidade nutricional da alimentação das crianças e adolescentes e aumentar as alternativas de renda das famílias de agricultores locais (REDE JUÇARA, 2014), objetivos estes a serem atingidos com este projeto em Caraguatatuba/SP.

\subsection{Objetivos gerais}

- Propor um programa de inclusão da polpa da fruta da juçara na merenda escolar em Caraguatatuba/SP proporcionando mais uma opção para resgatar hábitos alimentares regionais saudáveis e incentivar o seu consumo, atendendo o artigo 14 da Lei no 11.947/2009 do PNAE.

- Promover o consumo consciente da juçara e sua produção sustentável retirando a espécie do status de ameaçada de extinção.

\subsection{Objetivos específicos}

- Transmitir conhecimentos aos alunos e demais integrantes da rede de ensino de Caraguatatuba/SP quanto às vantagens do uso da polpa do fruto da juçara em suas refeições diárias e de suas famílias.

- Levar ao conhecimento de todos que o uso do fruto da palmeira juçara representa um produto promissor, com alto potencial de mercado, bem como geração de trabalho e renda para as comunidades locais. 


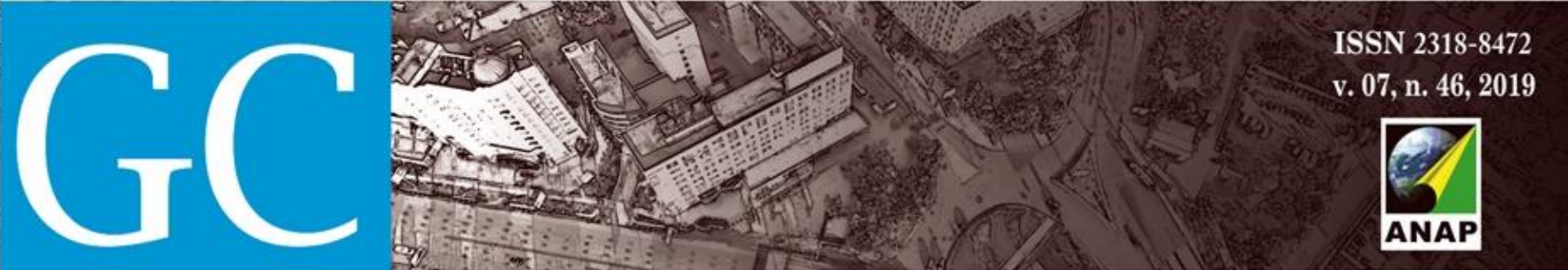

Revista Nacional de Gerenciamento de Cidades

- Orientar nutricionistas, alunos e funcionários da rede municipal de ensino e seus familiares da importância de se conservar essa espécie e, por conseguinte, o bioma Mata Atlântica.

\section{METODOLOGIA}

O programa de inclusão da polpa do fruto da palmeira juçara na merenda escolar em Caraguatatuba/SP foi desenvolvido em 2015 por meio de diversas atividades de forma a elevar o seu consumo e divulgar um produto regional, de boa qualidade nutricional, capaz de aumentar a renda das comunidades rurais locais, além de preservar uma palmeira quase extinta, utilizando uma forma de manejo sustentável.

\section{Atividade 1 - Apresentação às nutricionistas da composição nutricional e das operações de obtenção da polpa de juçara \\ Foram realizadas apresentações às nutricionistas da Rede Municipal de Ensino de Caraguatatuba quanto a composição nutricional da polpa do fruto da juçara (Tabela 1) e de algumas receitas. A polpa de juçara é uma ótima fonte energética, dada a elevada quantidade de lipídeos (3,17\%) e carboidratos totais $(6,75 \%)$, valores que estão acima dos teores encontrados para a polpa de açaí. Além disso é rica em minerais (cálcio e magnésio), em gorduras de ótima qualidade (mono e poli-insaturadas) e em antocianinas, um composto fitoquímico responsável pela sua cor roxa, que atua como antioxidante no corpo humano, prevenindo doenças cardiovasculares e degenerativas. Seu teor de fibras auxilia no bom funcionamento do intestino (SILVA, 2004).}




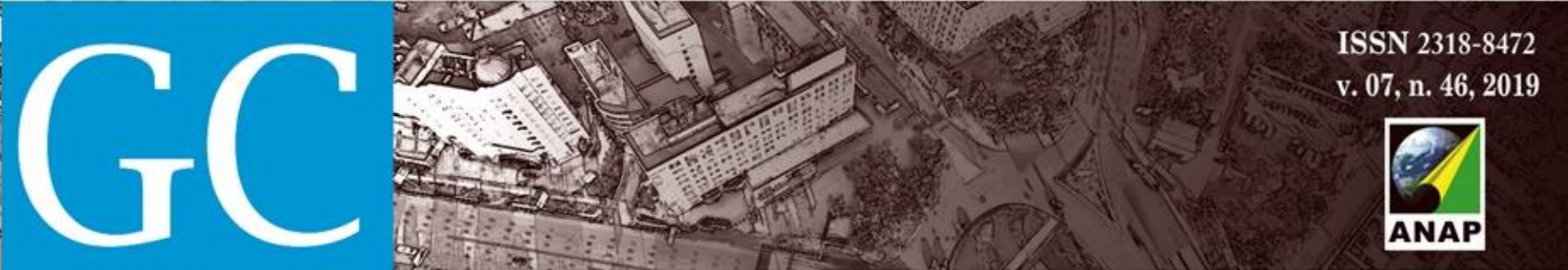

Revista Nacional de Gerenciamento de Cidades

Figura 1: Fluxograma das operações para obtenção dos produtos e subprodutos da polpa do fruto da juçara

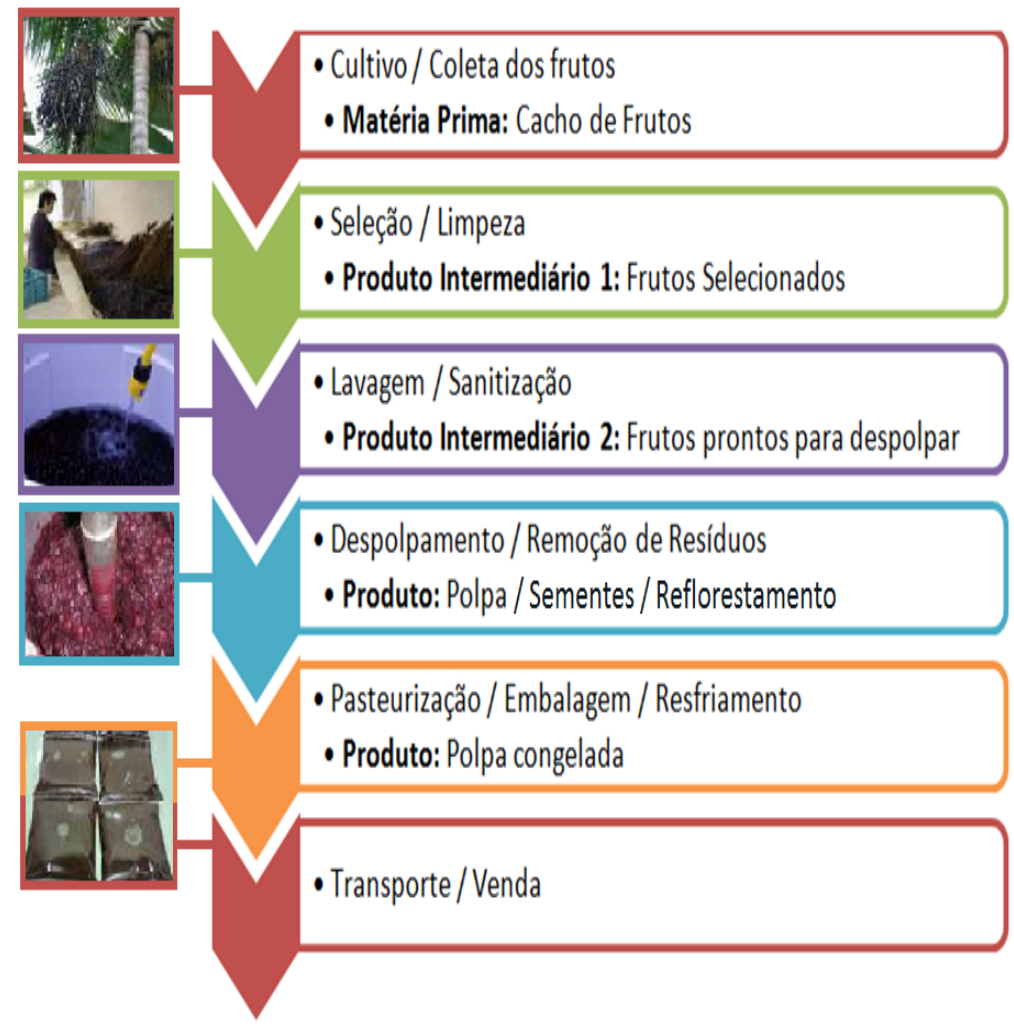

Fonte: as autoras, 2019

Atividade 2 - Teste de aceitabilidade da polpa de juçara realizado na Secretaria de Educação de Caraguatatuba/SP

No dia 11/05/2015 foi realizado o primeiro teste de aceitabilidade com 43 pessoas, todos adultos, no edifício da Secretaria Municipal de Educação de Caraguatatuba/SP. O suco de juçara foi preparado com laranja e banana e foi oferecido para degustação em copos plásticos, ocorrendo, posteriormente, uma explanação sobre os benefícios do consumo da polpa de juçara à saúde pelo seu alto valor nutricional. Após a degustação, as pessoas preencheram uma ficha com nome, função no trabalho e sua opinião, marcando sim para gostei e não para desgostei.

\section{Receita de suco de juçara com laranja e banana}

Ingredientes:

- 100 g de polpa congelada;

- suco de uma laranja;

- uma banana;

- adoçar a gosto (com mel, açúcar mascavo ou açúcar cristal). 



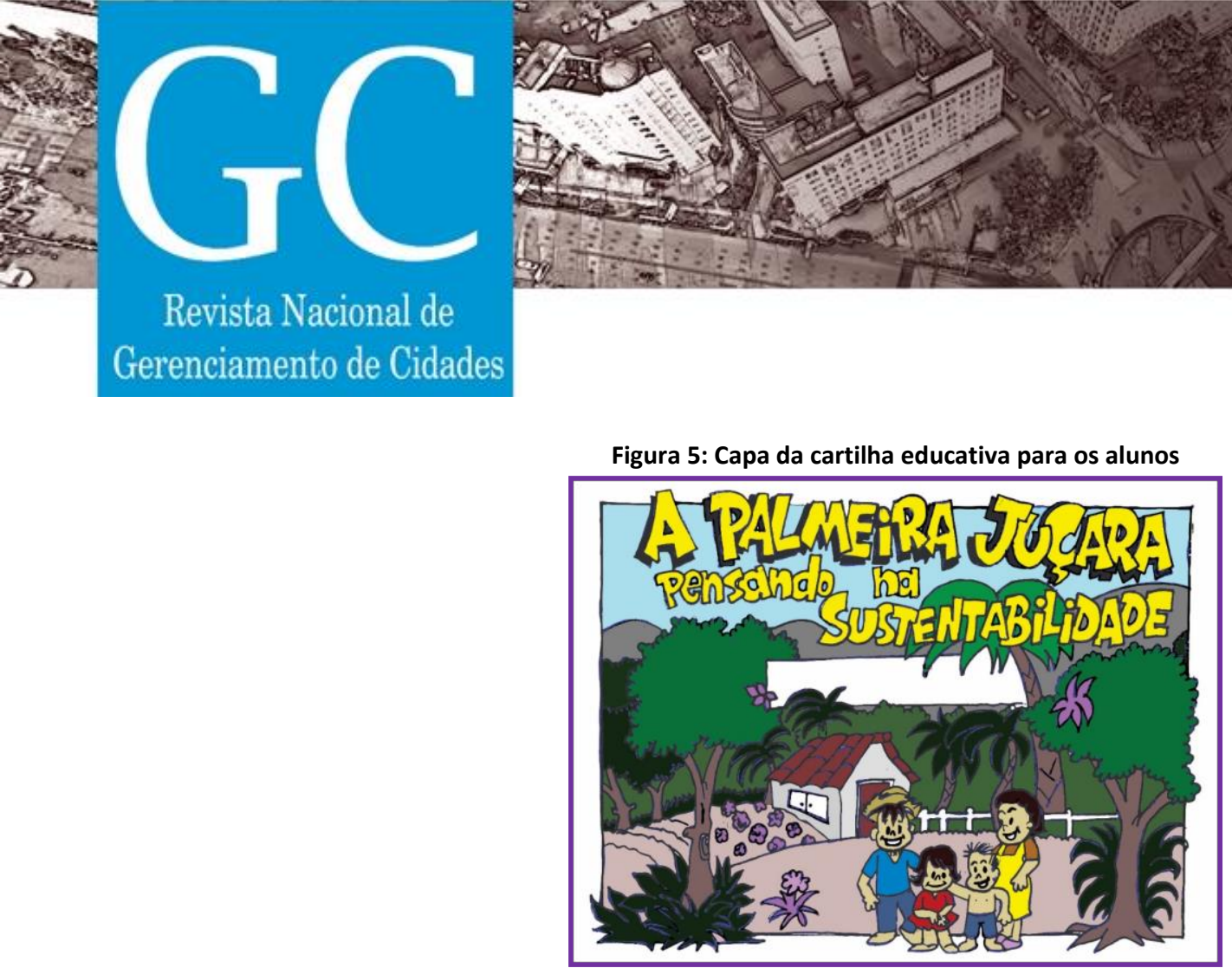

Fonte: as autoras, 2015

Disponível em: https://universidadebrasil.edu.br/portal/biblioteca/uploads/20190201180915.pdf

A cartilha contém uma história em quadrinhos para as crianças colorirem e conta a história de um agricultor e sua família moradora da Mata Atlântica que utilizam o palmito de juçara de maneira clandestina e aprendem a importância da conservação dessa palmeira em pé, utilizando seus frutos para o consumo e geração de renda familiar.

Conteúdo da cartilha: Apresentação da palmeira juçara; Conhecendo um pouco mais sobre essa palmeira; Como pode ser utilizada; O uso sustentável: O cultivo e o manejo de sementes e mudas; O manejo para produção da polpa.

\section{Atividade 5 - Aulas em powerpoint sobre a palmeira juçara}

Foram elaboradas aulas em powerpoint com o tema "A Palmeira Juçara" pelos estagiários da Rede Municipal que recebem formação mensal pela Secretaria de Educação. Na formação do dia 19/10/2015 foi entregue aos estagiários o material informativo com o conteúdo sobre a palmeira juçara e seu uso e estes elaboraram aulas interativas para os alunos de 10 ao 9 ㅇ ano com o conteúdo adaptado para cada série.

Assim, essas aulas de 50 minutos foram distribuídas e apresentadas aos alunos da Rede Municipal nos laboratórios de informática de cada Unidade Escolar, por seus professores, que explicaram, discutiram e orientaram os alunos sobre os temas abordados.

\section{Atividade 6 - Plantio de muda de palmeira juçara}

Na EMEF Masako Sone foi plantada juntamente com os alunos e funcionários, no dia 23/11/2015, uma muda da palmeira juçara (Figura 6) que foi identificada com nome e data de plantio, também foram explicados os tratos culturais necessários para a sua manutenção. Assim, objetivou-se com esta atividade que, ao cuidarem dessa palmeira, os alunos se familiarizassem com a espécie, divulgando para as suas famílias os conhecimentos adquiridos na escola. 


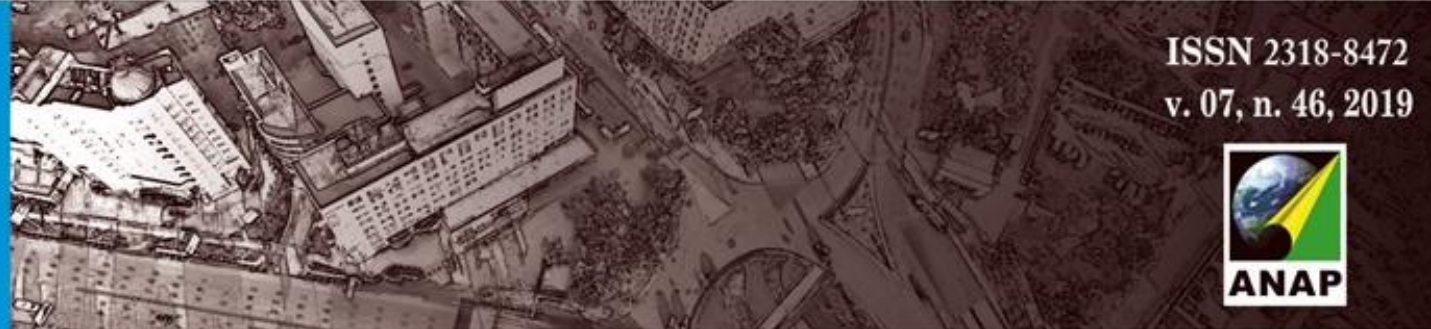

Revista Nacional de

Gerenciamento de Cidades

devem ser destinados à compra de produtos da agricultura familiar, onde o processo licitatório pode ser dispensado, desde que os preços estejam compatíveis com os praticados nos mercados local e os alimentos atendam a exigência de controle de qualidade (FNDE, 2016).

Para fins do PNAE, será considerado Educação Alimentar e Nutricional o conjunto de ações formativas, de prática contínua e permanente, transdisciplinar, intersetorial e multiprofissional que objetiva estimular a adoção voluntária de práticas e escolhas alimentares saudáveis, que colaborem para a aprendizagem, o estado de saúde do escolar e a qualidade de vida do indivíduo (FNDE, 2017).

Deve ser ressaltado que a legislação ambiental não é apenas punitiva, mais que isso, é pedagógica, pois busca através de seu texto orientar, conscientizar quanto à questão ambiental, no que tange à degradação, as queimadas, ao desmatamento, e toda conduta que possa de uma forma prejudicar o meio ambiente. A educação, a regulamentação e a fiscalização devem desempenhar papel preponderante para que comunidades possam coexistir e colaborar com a manutenção de um equilíbrio ecológico.

Souza (2015) investigando se o manejo de $E$. edulis para a produção da polpa pode funcionar como catalisador da conservação da biodiversidade e da melhoria dos meios de vida das populações humanas locais que habitam o entorno e o interior do Parque Estadual da Serra do Mar (PESM), Núcleos Santa Virgínia e Picinguaba, nos municípios de Natividade da Serra e Ubatuba, SP, verificou que o manejo da juçara contribuiu com o fortalecimento comunitário a partir da diversificação da produção familiar e o aumento de renda, inclusive para mulheres e jovens. $\mathrm{O}$ autor ressaltou que a colheita dos frutos feita de forma não destrutiva fez com que $70 \%$ dos cachos na área sobrassem, não prejudicando a fauna dependente dos frutos e a reprodução da espécie, ou seja, é possível garantir a reprodução da espécie enquanto se produz e comercializa. Cada grupo de agricultores colhe frutos de 10 a 30 palmeiras por dia, o que rende, em média, $87 \mathrm{~kg}$ de frutos e $45 \mathrm{~L}$ de polpa, garantindo renda diária.

Portanto, a educação, a regulamentação e a fiscalização podem desempenhar, no futuro, papel preponderante para que agricultores familiares ou mesmo comunidades que habitam o interior ou o entorno de Unidades de Conservação possam coexistir e colaborar com a manutenção de um equilíbrio ecológico local.

Por sua vez, em 25/02/2014 foi editada no Estado de São Paulo uma Resolução que estabelece critérios e procedimentos para plantio, coleta e exploração sustentáveis de espécies nativas da Mata Atlântica (Resolução SMA 14/2014), sendo a juçara a primeira espécie contemplada com regras específicas em anexo a esta resolução (SÃO PAULO, 2014).

No roteiro de orientação para a elaboração de Plano de Manejo Florestal Sustentável (PMFS) para a coleta de frutos e sementes de palmeira juçara (Euterpe edulis) desta Resolução consta: o responsável técnico pelo PMFS; a localização, com a indicação das coordenadas geográficas dos vértices da propriedade e das unidades de manejo; o plano de colheita, com a estimativa de quantidade total de frutos e sementes em quilogramas por hectare por ano, sendo que a coleta dos frutos e sementes não deverá impactar negativamente as populações naturais da palmeira 

